\title{
EVALUASI PERKERASAN JALAN KAKU (RIGID PAVEMENT) PADA JALAN SM RAJA MEDAN DENGAN METODE BINA MARGA
}

\author{
Ros Anita Sidabutar', Yetty Riris Saragi'), \\ Humisar Pasaribu ${ }^{3)}$, Maruli Pardede ${ }^{4)}$, Torang Hutabarat ${ }^{5)}$ \\ Fakultas Teknik Universitas HKBP Nommensen, Medan \\ Email: $\underline{\text { rosanita_sidabutar@yahoo.com }}{ }^{1)}$, yettyririssaragi@yahoo.com ${ }^{2)}$, \\ pasaribu.humisar@yahoo.com ${ }^{3)}$
}

\begin{abstract}
The Sisingamangaraja road section is a means of land transportation that is devoted to two or more axle vehicles with the aim of shortening the distance and travel time from one place to another, as well as an infrastruture that is needed to support development. The design of the Sisingamangaraja - Lubuk Pakam road pavement consisting of a cement concrete slab as a foundation layer and a foundation laver above the subgrade.

The purpose of this study was to evaluate the thickness of the pavement using the Highways Method. The research method used is the secondary data collection method. The data collected include traffic data, concrete data, soil data, vehicle axle free data, CBR modulus of subgrade.

Plaanning the thickness of the road pavement concrete slab using the Highways Method obtained $300 \mathrm{~mm}$. A planner is expected to have "felling engineering" supported by extensice knowledge and experience gained in the field.
\end{abstract}

Keywords : Pavements, Rigid pavements, Highways Method

Abstrak
Ruas Jalan Sisingamangaraja merupakan sarana transportasi angkutan darat yang dikhususkan untuk kendaraan bersumbu dua atau lebih dengan tujuan mempersingkat jarak dan waktu tempuh dari satu tempat ke tempat lain, dan juga suatu prasarana yang sangat dibutuhkan dalam menunjang permbangunan. Desain ruas Jalan Sisingamangaraja - Lubuk Pakam menggunakan perkerasan kaku. Perkerasan kaku (rigid pavement) adalah suatu perkerasan jalan yang terdiri atas plat beton semen sebagai lapis pondasi dan lapis pondadsi di atas tanah dasar.

Tujuan dari penelitian ini adalah untuk mengevaluasi tebal perkerasan dengan Metode Bina Marga. Metode penelitian yang dilakukan adalah dengan metode pengumpulan data sekunder. Data yang dikumpulkan antara lain, data lalu lintas, data beton, data tanah, data bebas as kendaraan, CBR modulus tanah dasar.

Perencanaan tebal pelat beton perkerasan jalan dengan menggunakan metode Bina Marga didapatkan $300 \mathrm{~mm}$. Seorang perencana diharapkan memiliki "felling engineering” yang didukung oleh pengetahuan yang luas dan pengalaman yang didapatkan di lapangan.

Kata kunci : Perkerasan, Perkerasan Kaku, Metode Bina Marga 


\section{PENDAHULUAN}

Jenis perkerasan kaku atau juga disebut Rigid Pavement merupakan alternatif perkerasan di Indonesia yang cukup banyak digunakan dikarenakan cukup kuat dan tanah lebih lama dibandingkan dengan perkerasan lentur (flexible pavement). Saat ini penggunaan perkerasan kaku sudah banyak digunakan khususnya untuk jalan nasional ataupun jalan tol. Hal ini disebabkan karena pada ruas-ruas jalan tersebut kerap kali dilewati oleh kendaraan berat (heavy vehicle).

Kenaikan beban apda kendaraan yang melintasi permukaan jalan, pembebanan kendaraan yang berulang juga menimbulkan kerusakan jalan. Oleh karena itu, semestinya dalam perencanaan jalan hendaknya direncanakan dengan benar agar jalan tersebut menghasilkan jalan yang kuat dan tahan terhadap peningkatan volume lalu lintas dan iklim selama masih dalam umur rencana dengan tetap melakukan pemeliharaan perkerasan jalan baik rutin maupun secara berkala.

Adapun tujuan dari penelitian ini adalah untuk mengidentifikasi altenatif desain perkerasan kaku dengan menggunakan metode Bina Marga serta untuk mengetahui tebal perkerasan sesuai dengan umur dan standar yang dikeluarkan oleh Bina Marga.

\section{TINJAUAN PUSTAKA}

\section{PERKERASAN KAKU}

Perkerasan kaku (rigid pavement) adalah perkerasan yang menggunakan semen sebagai bahan pengikatnya, pelat beton dengan atau tanpa tulangan diletakkan di atas tanah dasar dengan atau tanpa lapis pondasi bawah.

Perkerasan beton semen terdiri atas empat (4) jenis yaitu perkerasan beton bersambung tanpa tulang, perkerasan beton dengan tulangan, perkerasan beton semen menerus dengan tulangan dan perkerasan beton semen pra-tegang. 
Perkerasan beton adalah struktur yang terdiri atas pelat beton semen yang bersambung (tidak menerus) tanpa atau dengan tulangan, atau menerus dengan tulangan terletak di atas lapis pondasi bawah atau tanah dasar, atau lapis permukaan beraspal.

Pada perkerasan beton semen, daya dukung perkerasan terutama diperoleh dari pelat beton. Sifat, daya dukung dan keseragaman tanah dasar sangat mempengaruhi keawetan dan kekuatan perkerasan beton semen. Faktor-faktor yang perlu diperhatikan adalah kadar air pemadatan, kepadatan dan permukaan kadar air selama masa pelayanan. Lapis pondasi bawah pada perkerasan beton semen adalah bukan merupakan bagian utama yang memikul beban tetapi berfungsi untuk :

a) Mengendalikan pengaruh kembang susut tanah dasar.

b) Mencegah instrusi dan pemompaan pada sambungan, retakan dan tepi-tepi pelat.

c) Memberi dukungan yang lebih baik dan seragam pada pelat.

d) Sebagai perkerasan lantai kerja selama pelaksanaan.

\section{BETON SEMEN}

Kekuatan beton harus dinyatakan dalam nilai kuat tarik lentur (flexible pavements) umur 28 hari, yang didapat dari hasil pengujian dengan pembebanan tiga (3) titik (ASTM C-78 $)^{2}$ yang besarnya secara tipikal sekitar $3-5 \mathrm{MPa}\left(30-50 \mathrm{~kg} / \mathrm{cm}^{2}\right)$ kuat tarik lentur beton yang diperkuat dengan bahan serat penguat seperti serat baja, aramit atau serat beton, harus mencapai kuat tarik lentur $5-5,5 \mathrm{MPa}\left(50-55 \mathrm{~kg} / \mathrm{cm}^{2}\right)$. Kekuatan rencana harus dinyatakan dengan kuat tarik lentur karakteristik yang dibulatkan hingga 0,25 MPa (2,5 $\mathrm{kg} / \mathrm{cm}^{2}$ ) terdekat. Hubungan antara kuat tekan karakteristik dengan kuat tarik lentur beton didekati dengan persamaan berikut :

$$
\begin{aligned}
& f_{c f}=K\left(f^{\prime} c\right)^{0,50}(\mathrm{MPa}) \text { atau......... } \\
& f_{c f}=3,13 K\left(f^{\prime} c\right)^{0,50}\left(\mathrm{~kg} / \mathrm{cm}^{2}\right) .
\end{aligned}
$$

\section{Dimana :}

f'c : kuat tekan beton karakteristik 28 hari $\left(\mathrm{kg} / \mathrm{cm}^{2}\right)$

fcf : kuat tekan lentur beton karakteristik 28 hari $\left(\mathrm{kg} / \mathrm{cm}^{2}\right)$

$\mathrm{K} \quad$ : konstanta 0,7 untuk agregat tidak pecah dan 0,75 untuk agregat pecah 
Kuat tarik lentur dapat juga ditentukan dari hasil uji kuat tarik belah beton yang dilakukan berdasarkan SNI 03-2491-1991 ${ }^{1}$ sebagai berikut :

$$
\begin{aligned}
& f_{c f}=1,37 f c s(\mathrm{MPa}) \ldots \ldots . . \\
& f_{c f}=13,44 f c s\left(\mathrm{~kg} / \mathrm{cm}^{2}\right)
\end{aligned}
$$

\section{Dimana :}

fcs : kuat tarik belah beton karakteristik 28 hari

Beton dapat diperkuat dengan serat baja (steel-fibre) untuk meningkatkan kuat tarik lenturnya dan mengendalikan retak pada pelat khususnya untuk bentuk tidak lazim. Serat baja dapat digunakan pada campuran beton, untuk jalan tol, putaran dan pemberhentian bus.

\section{METODE PENELITIAN}

Dalam penelitian ini data-data pendukung didapatkan dari proyek pembangunan Jl. SM Raja Medan sebagai data sekunder. Adapun data-data sekunder yang digunakan adalah sebagai berikut :

1) Data lapangan, antara lain :

a) Boring log yaitu data jenis dan warna lapisan tanah, tebal lapisan serta letak muka air

b) CBR lapangan

2) Data pengujian laboratorium, antara lain :

a) Data soil properties berupa specific gravity, kohesi (c), sudut geser (Ø), berat isi tanah $(\gamma)$, water content $(\mathrm{w})$ dan void ratio $(\mathrm{e})$

b) Data liquid dan plastis limit

3) Peta lokasi dan gambar trase jalan 
4) Lalu lintas harian rata-rata, yaitu mengenai jenis dan volume kendaraan yang melewati jalan tersebut

5) Data topografi

\section{ANALISIS DAN HASIL}

\section{DATA VOLUME LALU LINTAS}

Pada lokasi penelitian selanjutnya dibagi menjadi dua (2) segmen ruas jalan yaitu Segmen 1 (Arah ke Medan) dan Segmen 2 (Arah ke Lubuk Pakam). Hasil perhitungan volume lalu lintas dijabarkan pada Tabel 1.

Tabel 1. Volume Lalu Lintas (Kend/hari)

\begin{tabular}{|c|c|c|c|}
\hline \multicolumn{2}{|c|}{ Medan - Lubuk Pakam } & \multicolumn{2}{c|}{ Lubuk Pakam - Medan } \\
\hline Golongan & $\begin{array}{c}\text { Jumlah } \\
\text { Kendaraan }\end{array}$ & Golongan & $\begin{array}{c}\text { Jumlah } \\
\text { Kendaraan }\end{array}$ \\
\hline 2 & 9232 & 2 & 9389 \\
\hline 3 & 1809 & 3 & 1926 \\
\hline 4 & 1769 & 4 & 1455 \\
\hline $5 \mathrm{a}$ & 163 & $5 \mathrm{a}$ & 201 \\
\hline $5 \mathrm{~b}$ & 281 & $5 \mathrm{~b}$ & 228 \\
\hline $6 \mathrm{a}$ & 486 & $6 \mathrm{a}$ & 274 \\
\hline $6 \mathrm{~b}$ & 2179 & $6 \mathrm{~b}$ & 1847 \\
\hline $7 \mathrm{a} 1$ & 30 & $7 \mathrm{a} 1$ & 5 \\
\hline $7 \mathrm{a} 2$ & 1216 & $7 \mathrm{a} 2$ & 1168 \\
\hline $7 \mathrm{~b}$ & 0 & $7 \mathrm{~b}$ & 0 \\
\hline $7 \mathrm{c} 1$ & 324 & $7 \mathrm{c} 1$ & 167 \\
\hline $7 \mathrm{c} 2 \mathrm{a}$ & 38 & $7 \mathrm{c} 2 \mathrm{a}$ & 20 \\
\hline $7 \mathrm{c} 2 \mathrm{~b}$ & 72 & $7 \mathrm{c} 2 \mathrm{~b}$ & 30 \\
\hline $7 \mathrm{c} 3$ & 140 & $7 \mathrm{c} 3$ & 100 \\
\hline \multicolumn{2}{|c|}{ Sumber $:$ Hasil penelitian $(2019)$} & & \\
\hline
\end{tabular}

\section{PERHITUNGAN LALU LINTAS HARIAN RATA-RATA TAHUN KE-n}

Berdasarkan hasil survey pada ruas jalan yang sudah dilakukan, jumlah lalu lintas harian rata-rata kendaraan dari golongan I sampai golongan V seperti yang dijabarkan pada 
Tabel 2. Maka untuk perencanaan perkerasan jalan 2 lajur dan 2 arah diambilkan faktor pertumbuhan lalu lintas $5 \%$ akibat pengaruh pertumbuhan jumlah penduduk dan tingkat ekonomi masyarakat setempat, dan untuk umur rencana perkerasan jalan 20 tahun.

Tabel 2. Data Lalu Lintas Harian Rata-rata 2 arah/hari

\begin{tabular}{|c|c|c|c|c|c|c|}
\hline $\begin{array}{c}\text { Tipe } \\
\text { Kendaraan }\end{array}$ & $\begin{array}{c}\text { Golongan } \\
\text { Kendaraan }\end{array}$ & $\begin{array}{l}\text { LHR } \\
2015\end{array}$ & $\mathrm{i}=\mathbf{5 \%}$ & LHR & $\mathbf{E}$ & $\mathbf{C}$ \\
\hline $\begin{array}{l}\text { - Sedan } \\
\text { - Jeep } \\
\text { - Station wagon }\end{array}$ & 2 & 18621 & 0,05 & 102,4155 & 0,0055 & 0,3 \\
\hline $\begin{array}{l}\text { - Oplet } \\
\text { - Pickup oplet } \\
\text { - Mini bus } \\
\text { - Combi }\end{array}$ & 3 & 3734 & 0,05 & 282,2904 & 0,0055 & 0,3 \\
\hline $\begin{array}{l}\text { - Pickup } \\
\text { - Mikro truk } \\
\text { - Mobil } \\
\text { hantaran }\end{array}$ & 4 & 3224 & 0,05 & 1008,1448 & 0,0055 & 0,3 \\
\hline - Bus kecil & $5 a$ & 365 & 0,05 & 145,27 & 0,065 & 0,45 \\
\hline - Bus besar & $5 b$ & 508 & 0,05 & 448,6148 & 0,332 & 0,45 \\
\hline $\begin{array}{l}\text { - Truk ringan } 2 \\
\text { sumbu }\end{array}$ & $6 a$ & 760 & 0,05 & 341,848 & 0,356 & 0,45 \\
\hline $\begin{array}{l}\text { - Truk berat } 2 \\
\text { sumbu }\end{array}$ & $6 b$ & 4026 & 0,05 & 891,759 & 0,792 & 0,45 \\
\hline $\begin{array}{l}\text { - Truk } 3 \text { sumbu } \\
\text { tunggal }\end{array}$ & $7 \mathrm{a} 1$ & 36 & 0,05 & 25,0776 & 5,235 & 0,45 \\
\hline $\begin{array}{l}\text { - Truk } 3 \text { sumbu } \\
\text { tandem }\end{array}$ & $7 \mathrm{a} 2$ & 2384 & 0,05 & 1675,4752 & 0,049 & 0,45 \\
\hline - Truk gandeng & $7 b$ & 0 & 0,05 & 0 & 1,825 & 0,45 \\
\hline - Truk 4 sumbu & $7 \mathrm{c} 1$ & 510 & 0,05 & 1524,645 & 3,017 & 0,45 \\
\hline $\begin{array}{l}\text { - Truk } 5 \text { sumbu } \\
\text { tandem }\end{array}$ & $7 \mathrm{c} 2 \mathrm{a}$ & 58 & 0,05 & 180,9194 & 0,509 & 0,45 \\
\hline $\begin{array}{l}\text { - Truk } 5 \text { sumbu } \\
\text { tripel }\end{array}$ & $7 c 2 b$ & 102 & 0,05 & 433,704 & 0,241 & 0,45 \\
\hline - Truk 6 sumbu & $7 \mathrm{c} 3$ & 240 & 0,05 & 772,032 & 0,289 & 0,45 \\
\hline
\end{tabular}

\section{PERHITUNGAN TEBAL PERKERASAN KAKU}


Hasil perhitungan tegangan setara dan faktor erosi pada penelitian ini dijabarkan pada Tabel 3 dan perhitungan faktor erosi tanpa ruji dan dengan ruji/beton bertulang dijabarkan pada Tabel 4.

Tabel 3. Penentuan Tegangan Setara dan Faktor Erosi

\begin{tabular}{|c|c|c|c|c|c|}
\hline \multirow{2}{*}{$\begin{array}{c}\text { Tebal Slab } \\
(\mathbf{m m})\end{array}$} & $\begin{array}{c}\text { CBR Efektif } \\
\text { Tanah Dasar } \\
(\boldsymbol{\%})\end{array}$ & \multicolumn{4}{|c|}{ Tegangan Setara (TE) } \\
\cline { 2 - 6 } & $\mathbf{S}$ & 0,49 & 0,86 & 0,79 & 0,58 \\
\hline \multirow{5}{*}{300} & 10 & 0,48 & 0,81 & 0,73 & 0,56 \\
\cline { 2 - 6 } & 15 & 0,47 & 0,78 & 0,70 & 0,53 \\
\cline { 2 - 6 } & 20 & 0,46 & 0,77 & 0,69 & 0,52 \\
\cline { 2 - 6 } & 25 & 0,48 & 0,76 & 0,67 & 0,51 \\
\cline { 2 - 6 } & 35 & 0,46 & 0,73 & 0,64 & 0,49 \\
\cline { 2 - 6 } & $\mathbf{4 3}$ & $\mathbf{0 , 4 5 5}$ & $\mathbf{0 , 7 1 4}$ & $\mathbf{0 , 6 1 9}$ & $\mathbf{0 , 4 7 4}$ \\
\cline { 2 - 6 } & 50 & 0,45 & 0,70 & 0,60 & 0,46 \\
\cline { 2 - 6 } & 75 & 0,45 & 0,67 & 0,57 & 0,45 \\
\hline
\end{tabular}

Sumber : Hasil penelitian (2019)

Tabel 4. Penentuan Faktor Erosi (i)

\begin{tabular}{|c|c|c|c|c|c|c|c|c|c|}
\hline \multirow{4}{*}{$\begin{array}{c}\text { Tebal } \\
\text { Slab } \\
(\mathbf{m m})\end{array}$} & $\begin{array}{c}\text { CBR } \\
\text { Efektif } \\
\text { Tanah } \\
\text { Dasar } \\
(\mathbf{\%})\end{array}$ & STRT & STRG & STdRG & STrRG & STRT & STRG & STdRG & STrRG \\
\cline { 2 - 10 } & 5 & 1,57 & 2,17 & 2,42 & 2,52 & 1,32 & 1,93 & 2,16 & 2,32 \\
\hline \multirow{6}{*}{300} & 10 & 1,55 & 2,15 & 2,36 & 2,44 & 1,30 & 1,91 & 2,10 & 2,24 \\
\cline { 2 - 10 } & 15 & 1,53 & 2,14 & 2,33 & 2,40 & 1,29 & 1,89 & 2,07 & 2,20 \\
\cline { 2 - 10 } & 20 & 1,52 & 2,13 & 2,31 & 2,37 & 2,28 & 1,88 & 2,05 & 2,18 \\
\cline { 2 - 10 } & 25 & 1,51 & 2,12 & 2,29 & 2,35 & 1,27 & 1,87 & 2,03 & 2,15 \\
\cline { 2 - 10 } & 35 & 1,49 & 2,10 & 2,25 & 2,30 & 1,25 & 1,85 & 1,99 & 2,09 \\
\cline { 2 - 9 } & $\mathbf{4 3}$ & $\mathbf{1 , 4 8 5}$ & $\mathbf{2 , 0 8 9}$ & $\mathbf{2 , 2 2 3}$ & $\mathbf{2 , 2 6 8}$ & $\mathbf{1 , 2 3 9}$ & $\mathbf{1 , 8 3 9}$ & $\mathbf{1 , 9 6 9}$ & $\mathbf{2 , 0 5 8}$ \\
\cline { 2 - 9 } & 50 & 1,48 & 2,08 & 2,20 & 2,24 & 1,23 & 1,83 & 1,95 & 2,03 \\
\cline { 2 - 9 } & 75 & 1,46 & 2,06 & 2,15 & 2,17 & 1,81 & 1,81 & 1,90 & 1,95 \\
\hline
\end{tabular}

Sumber : Hasil penelitian (2019)

\section{PENENTUAN KUAT LENTUR BETON}


Nilai kuat lentur beton dipengaruhi oleh nilai kuat tekan beton. Nilai kuat tekan beton (f'c) yang diperoleh sesuai pengujian sebesar $479 \mathrm{~kg} / \mathrm{cm}^{2}$ sehingga nilai kuat tekan tersebut memenuhi syarat kuat tekan minimum sebebsar $450 \mathrm{~kg} / \mathrm{cm}^{2}$. Nilai kuat tekan (f'c) yang digunakan sebagai parameter desain adalah sebesar $450 \mathrm{~kg} / \mathrm{cm}^{2}$. Dari hasil perhitungan maka didapatkan bahwa nilai kuat tekan beton (f'c) pada penelitian ini adalah sebesar 4,98 $\mathrm{MPa}$ atau dibulatkan menjadi $5 \mathrm{MPa}$.

\section{MENENTUKAN FAKTOR PERTUMBUHAN LALU LINTAS}

Volume lalu lintas akan bertambah sesuai dengan umur rencana atau sampai tahap dimana kapasitas jalan dicapai dengan faktor pertumbuhan lalu lintas. Nilai faktor pertumbuhan lalu lintas yang digunakan pada penelitian ini adalah 33,06.

\section{MENENTUKAN JUMLAH SUMBU KENDARAAN NIAGA}

Jumlah sumbu kendaraan niaga dipengaruhi oleh koefisien distribusi kendaraan (C). Berdasarkan perhitungan nilai koefisien distribusi kendaraan (C) yang sudah ditentukan sebelumnya yaitu sebesar 0,7 maka nilai JSKN (Jumlah Sumbu Kendaraan Niaga) adalah sebesar 151,418 x $10^{6}$. Perhitungan nilai perkerasan kaku untuk jalan dengan beban lalu lintas dijabarkan pada Tabel 5.

Tabel 5. Perkerasan Kaku untuk Jalan dengan Beban Lalu Lintas

\begin{tabular}{|c|c|c|c|c|c|}
\hline Struktur Perkerasan & R1 & R2 & R3 & R4 & R5 \\
\hline $\begin{array}{l}\text { Kelompok sumbu } \\
\text { kendaraan berat } \\
\text { (overloaded) }\end{array}$ & $<4,3 \times 10^{6}$ & $<8,6 \times 10^{6}$ & $<25,8 \times 10^{6}$ & $<43 \times 10^{6}$ & $<86 \times 10^{6}$ \\
\hline Dowel dan bahu beton & \multicolumn{5}{|c|}{$\mathrm{Ya}$} \\
\hline $\begin{array}{l}\text { Struktur Perkerasan } \\
(\mathrm{mm})\end{array}$ & $\mathbf{R 1}$ & $\mathbf{R 2}$ & $\mathbf{R 3}$ & $\mathbf{R 4}$ & $\mathbf{R 5}$ \\
\hline Tebal pelat beton & 265 & 275 & 285 & 295 & 305 \\
\hline Lapisan pondasi LMC & \multicolumn{5}{|c|}{150} \\
\hline $\begin{array}{l}\text { Lapisan pondasi agregat } \\
\text { kelas } A^{12}\end{array}$ & \multicolumn{5}{|c|}{150} \\
\hline
\end{tabular}

\section{MENENTUKAN SEGMEN PELAT BETON}


Untuk segmen pelat yang disarankan Bina Marga harus sesuai dengan perbandingan $<$ 1,25. Sehingga dalam kasus J1 SM Raja ukuran segmen pelat beton rencana adalah lebar pelat sebesar 3,75 $\mathrm{m}$. Untuk mengetahui apakkah ukuran segmen pelat memenuhi syarat Bina Marga dilakukan perhitungan sebagai berikut.

$$
\begin{aligned}
\text { Panjang pelat beton } & =\text { lebar pelat } \mathrm{x} \text { perbandingan } \\
\text { maksimum } & =3,75 \times 1,25 \\
& =4,6875 \mathrm{~mm}=4,5 \mathrm{~mm} \\
\text { Perbandingan lebar } & =\text { panjang pelat }: \text { lebar pelat } \\
\text { dan panjang pelat } & =4,5: 3,75 \\
& =1,2 \mathrm{~mm}<1,25 \mathrm{~mm} \\
& =\text { memenuhi syarat }
\end{aligned}
$$

Maka ukuran segmen pelat beton yang digunakan sebagai perkerasan ruas J1 SM Raja yaitu panjang pelat $4,5 \mathrm{~mm}$ dan lebar pelat $3,75 \mathrm{~mm}$.

\section{PERHITUNGAN PENULANGAN}

Fungsi dari sambungan memanjang (tier bar) adalah untuk memegang antar slab sehingga tetap teguh, tidak bergeser dan juga direncanakan untuk menahan gaya tarik namun tidak untuk memindahkan beban. Pada penelitian ini, perhitungan sambungan memanjang dijabarkan sebagai berikut :

$$
\begin{aligned}
\text { At } & =204 \times \mathrm{b} \times \mathrm{h} \\
& =204 \times 3,75 \times 0,3 \\
& =229,5 \mathrm{~mm} \\
\mathrm{~L} & =38,3 \times \varnothing+75 \\
& =38,3 \times 16+75 \\
& =687,8 \mathrm{~mm}
\end{aligned}
$$

Maka ditentukan bahwa luas penampang tulangan parameter panjang sambungan (At) adalah 229,5 $\mathrm{mm}$ dan panjang batang pengikat (L) adalah 687,8 $\mathrm{mm}$.

Dowel bars merupakan sepotong baja polos dan lurus yang digunakan sebagai perangkat transver beban, dengan diameter dan panjang yang telah ditetapkan pada peraturan Bina Marga. Maka diameter dowel (d) yang ditentukan adalah 1,5 inchi. Perhitungan penggunaan besi dowel dijabarkan pada Tabel 6. 
Tabel 6. Penggunaan Besi Dowel

\begin{tabular}{|c|c|c|c|c|c|c|c|}
\hline \multicolumn{2}{|c|}{ Tebal pelat } & \multicolumn{2}{c|}{ Diameter } & \multicolumn{2}{c|}{ Panjang } & \multicolumn{2}{c|}{ Jarak } \\
\hline inchi & $\mathbf{m m}$ & inchi & $\mathbf{m m}$ & inchi & $\mathbf{m m}$ & inchi & mm \\
\hline 6 & 150 & 1 & 19 & 18 & 450 & 12 & 300 \\
\hline 7 & 175 & 1 & 25 & 18 & 450 & 12 & 300 \\
\hline 8 & 200 & 1 & 25 & 18 & 450 & 12 & 300 \\
\hline 9 & 225 & 1 & 32 & 18 & 450 & 12 & 300 \\
\hline 10 & 250 & 1 & 32 & 18 & 450 & 12 & 300 \\
\hline 11 & 275 & 1 & 32 & 18 & 450 & 12 & 300 \\
\hline 12 & 300 & 1 & 38 & 18 & 450 & 12 & 300 \\
\hline
\end{tabular}

Sumber : Hasil penelitian (2019)

\section{KESIMPULAN}

Berdasarkan analisis yang telah dilakukan pada dapat diambil kesimpulan bahwa tebal struktur perkerasan kaku J1 SM Raja berdasarkan perhitungan yang telah dilakukan adalah tebal pelat adalah $30 \mathrm{~cm}$, tebal lean concrete adalah $10 \mathrm{~cm}$ dan tebal pondasi agregat adalah $15 \mathrm{~cm}$.

\section{DAFTAR PUSTAKA}

Badan Standarisasi Nasional. (1991). Metode Pembuatan dan Perawatan Benda Uji Beton di Laboratorium SNI 03-2493-1991. Jakarta.

Callister, W. D. J. (1998). Annual Book of ASTM Standars. Standard Test Method for EndQuench Test for Hardenability of Seel, American Society for Testing and Materials. John Wiley \& Sons, Inc. United Stated of America.

Direktorat Jenderal Bina Marga. (2003). Perencanaan Perkerasan Jalan Beton Semen. Departemen Permukiman dan Prasarana Wilayah. 